\title{
The Mouse Cochlea Expresses a Local Hypothalamic- Pituitary-Adrenal Equivalent Signaling System and Requires Corticotropin-Releasing Factor Receptor 1 to Establish Normal Hair Cell Innervation and Cochlear Sensitivity
}

\author{
Christine E. Graham and Douglas E. Vetter \\ Department Neuroscience, Tufts University School of Medicine, Boston, Massachusetts 02111
}

Cells of the inner ear face constant metabolic and structural stress. Exposure to intense sound or certain drugs destroys cochlea hair cells, which in mammals do not regenerate. Thus, an endogenous stress response system may exist within the cochlea to protect it from everyday stressors. We recently described the existence of corticotropin-releasing factor (CRF) in the mouse cochlea. The CRF receptor type 1 (CRFR1) is considered the primary and canonical target of CRF signaling, and systemically it plays an essential role in coordinating the body-wide stress response via activation of the hypothalamic-pituitary-adrenal (HPA) axis. Here, we describe an essential role for CRFR1 in auditory system development and function, and offer the first description of a complete HPA equivalent signaling system resident within the cochlea. To reveal the role of CRFR1 activation in the cochlea, we have used mice carrying a null ablation of the CRFR1 gene. CRFR $1^{-1-}$ mice exhibited elevated auditory thresholds at all frequencies tested, indicating reduced sensitivity. Furthermore, our results suggest that CRFR1 has a developmental role affecting inner hair cell morphology and afferent and efferent synapse distribution. Given the role of HPA signaling in maintaining local homeostasis in other tissues, the presence of a cochlear HPA signaling system suggests important roles for CRFR1 activity in setting cochlear sensitivity, perhaps both neural and non-neural mechanisms. These data highlight the complex pleiotropic mechanisms modulated by CRFR1 signaling in the cochlea.

\section{Introduction}

The ability of the hypothalamic-pituitary-adrenal (HPA) axis to modify auditory function has been known for $>3$ decades. The HPA axis is activated as a systemic stress response. Corticotropinreleasing factor (CRF) is released from the hypothalamus and binds CRF receptor type 1 (CRFR1) in the pituitary, inducing cleavage of pro-opiomelanocortin (POMC) to generate its end products, including adrenocorticotropic hormone (ACTH). ACTH is secreted into the bloodstream and binds the melanocortin 2 receptor $(\mathrm{MC} 2 \mathrm{R})$ on the adrenal cortex, stimulating production and release of several steroid hormones including glucocorticoids (cortisol in humans, corticosterone in rodents) into the systemic circulation. Heightened auditory sensitivity was identified in patients with adrenocorticosteroid insufficiency

\footnotetext{
Received Aug. 30, 2010; revised 0ct. 18, 2010; accepted Nov. 8, 2010.

This research was funded by National Institutes of Health (NIH) Grant R01DC006258 to D.E.V. Confocal microscopy was performed at the Tufts Center for Neuroscience Research Imaging Core, funded by National Institutes of Health Grant P30NS047243. We acknowledge Dr. M. C. Liberman for his generous support in granting access to and use of his auditory physiology setup, and use of the Amira imaging software; Dr. Paul Sawchenko for providing CRFR1-GFP transgenic mice and Dr. Carlos Arias for skillful assistance with the CRFR1-GFP mice; and Drs. Wylie Vale and Kuo-Fen Lee for providing initial CRFR1 line from which all CRFR $1^{-/-}$and $C R F R 1^{+/+}$mice were generated for this study.

Correspondence should be addressed to Douglas E. Vetter, Tufts University School of Medicine, 136 Harrison Avenue, Boston, MA 02111. E-mail: douglas.vetter@tufts.edu.

C.E.G.'s present address: The Jean Mayer USDA Human Nutrition Research Center on Aging, Tufts University, 711 Washington Street, Boston, MA 02111.

DOl:10.1523/JNEUROSCI.4545-10.2011

Copyright $\odot 2011$ the authors $\quad 0270-6474 / 11 / 311267-12 \$ 15.00 / 0$
}

(Henkin et al., 1967; Powers, 1972) and in rats following adrenalectomy (Siaud et al., 2006), suggesting a correlation between auditory function and circulating levels of stress hormones. Subsequent work revealed glucocorticoid receptor expression in the cochlea (Rarey and Luttge, 1989), further indicating that circulating glucocorticoids modulate cochlear activity (ten Cate et al., 1992). Preconditioning experiments confirmed that HPA activation regulates auditory function. Mice subjected to restraint stress or low-level sound exposure before an acoustic insult exhibit diminished permanent auditory threshold shifts following the insult compared with nontreated mice (Wang and Liberman, 2002; Tahera et al., 2007). Moreover, restraint stress only confers protection if the trauma coincides with elevated levels of circulating corticosterone. Disruption of the HPA axis via adrenalectomy or administration of glucocorticoid antagonists abolishes the protective effect of sound conditioning (Tahera et al., 2007).

Given this evidence, it has been assumed that classic HPA signaling is the source of cochlear protection following preconditioning, and molecules underlying this effect are delivered to the inner ear via blood circulation. However, circulating corticosterone/cortisol levels undergo diurnal variation (Smith et al., 1998). In addition, the HPA axis is regulated by a number of internal and external stimuli. Therefore, it seems questionable that the cochlea would rely on a system controlled by so many variables for constitutive protection against routine cellular stress. Consistent with this, unilateral sound conditioning protects only the exposed ear (Yamasoba et al., 1999). Thus, a 
system-wide phenomenon cannot completely account for the protective effects of conditioning, and local signaling may be involved in preconditioning-induced protection.

The cochlea may have its own stress response system to adapt to everyday cellular stressors that can function independent of systemic HPA signaling. Several studies have described a local HPA equivalent signaling system in skin. Skin cells express CRFR1, POMC, ACTH, and MC2R, and are locally innervated by neurons containing CRF (Slominski et al., 1999). Activation of this local HPA equivalent system leads to local production and release of cortisol (Ito et al., 2005). Additionally, cells derived from adult retinal pigment epithelial cells (ARPE-19 cell line) also express an HPA equivalent signaling system (Zmijewski et al., 2007). Given that the cochlea contains both CRF (Graham et al., 2010) and glucocorticoid receptors (Rarey and Luttge, 1989), respectively the initiator and effector molecules for HPA-like signaling, we hypothesized that it might express a full HPAequivalent system, and that this system may be involved in homeostatic regulation of the cochlea, perhaps controlling cochlear sensitivity or other fundamental properties of the cochlea. Here, we show that the cochlea expresses POMC, ACTH, and MC2R in addition to CRF and CRFR1. We further reveal that elimination of CRFR1, the main target of CRF signaling and the initiator of HPA-like signaling, leads to impaired auditory function, abnormal inner hair cell (IHC) development, and innervation defects to hair cells, none of which are corticosterone dependent. These data highlight complex pleiotropic mechanisms modulated by CRFR1 and local HPA-equivalent signaling in the cochlea.

\section{Materials and Methods}

\section{Animals, housing, and drug treatment}

The generation and characterization of $C R F R 1^{-/-}$mice have been described previously (Smith et al., 1998). Mice were produced either as progeny of $C R F R 1^{+/+}$breeder pairs, or via CRFR $1^{+/-}$female by $C R F R 1^{-/-}$male breeders, except for glucocorticoid replacement experiments. The CRFR $1^{-1-}$ mice are generally produced by this breeding scheme because the offspring from CRFR $1^{-/-}$females exhibit developmental defects unless supplemental glucocorticoids are administered during gestation (Smith et al., 1998). Two glucocorticoid replacement therapy experiments (details below) were performed on CRFR $1^{-/-}$and CRFR $1^{+/+}$mice: (1) to assess glutamine synthetase (GS) expression levels and their dependency on circulating glucocorticoid levels; and (2) to assess whether $C R F R 1^{-/-}$auditory physiology defects observed stemmed from systemic versus local CRFR1 defects. To replace glucocorticoids in CRFR1 ${ }^{-/-}$mice, corticosterone (C2505, Sigma) was administered via the drinking water at a dosage of $0.25 \mathrm{mg} / \mathrm{ml}$, based on previous studies showing that this dosage was sufficient to rescue lung defects of pups born to CRFR1 ${ }^{-/-}$breeders (Smith et al., 1998). Because corticosterone was dissolved in $100 \%$ ethanol, mice were separated into three groups: no treatment control; vehicle-treated control; and corticosterone treated. Vehicle-treated mice received the equivalent amount of ethanol in their drinking water $(0.25 \%$ ethanol $)$ that corticosterone-treated mice received. For auditory physiology experiments, mice were administered corticosterone from embryonic day 12 (E12) onward. For GS Western blot experiments, mice were administered either corticosterone or vehicle from postnatal day 12 (P12) onward or throughout gestation (dams received treatments before plug date). The start time of treatment did not alter the effect on cochlear GS expression levels determined by Western blot, and therefore data from all mice were grouped together regardless of time of initiation of corticosterone (or vehicle) treatment. BAC (bacterial artificial chromosome) transgenic mice expressing green fluorescent protein (GFP) under the CRFR1 promoter (Justice et al., 2008) were used for CRFR1 localization experiments (mice provided by Dr. Paul Sawchenko, The Salk Institute for Biological Studies, La Jolla, CA).

\section{Immunolabeling}

HPA system visualization. For experiments examining expression of HPA components in the inner ear, cochleae from 10-month-old CRFR1-GFP mice were perfused with buffered $4 \%$ paraformaldehyde, postfixed for $1 \mathrm{~h}$, and then decalcified (8\% EDTA buffered in $1 \times$ PBS) for $5 \mathrm{~d}$ at $4^{\circ} \mathrm{C}$. Decalcified cochleae were cryoprotected in $10 \%$ sucrose for $2-4 \mathrm{~h}$ at room temperature and then moved to $30 \%$ sucrose overnight at $4^{\circ} \mathrm{C}$. Following cryoprotection, cochleae were gently perfused with octreotide (OCT), then immediately embedded in OCT and frozen in isopentane cooled with dry ice. Cryostat sections were cut $8 \mu \mathrm{m}$ thick and dried at $50^{\circ} \mathrm{C}$ for $10-20 \mathrm{~min}$ followed by a $10 \mathrm{~min}$ wash in $1 \times$ PBS before use. Mid-modiolar sections were incubated in blocking solution (5\% normal donkey serum and $0.5 \%$ Triton X-100 in $1 \times$ PBS) for $1 \mathrm{~h}$ at room temperature and incubated in primary antibody solution containing $1 \%$ normal donkey serum and $0.1 \%$ Triton X-100 overnight at room temperature. Primary antibodies included the following: polyclonal goat anti-GFP (1:500, Rockland); polyclonal rabbit anti-CRF (1:500, Millipore Bioscience Research Reagents); polyclonal rabbit anti-POMC (1: 2000, Phoenix Pharmaceuticals, Inc., gift from Dr. Ron Lechan, Tufts University School of Medicine, Boston, MA); polyclonal rabbit antiACTH (1:1000, gift from Dr. Ron Lechan, Tufts University School of Medicine); and polyclonal rabbit anti-MC2R (1:100, Santa Cruz Biotechnology). "No primary" control sections were incubated in the same primary solution with $1 \times$ PBS volumetrically replacing primary antibody. Following primary incubation, sections underwent three $15 \mathrm{~min}$ washes in $1 \times$ PBS. They were then incubated with secondary antibody in a solution of $1 \%$ normal donkey serum and $0.1 \%$ Triton X-100 for $1-1.5$ $\mathrm{h}$ at room temperature. Secondary antibodies included Alexa488conjugated donkey anti-goat (1:500, Invitrogen) and Alexa594conjugated donkey anti-rabbit (1:500, Invitrogen). Following secondary incubation, sections were washed three times over $1 \mathrm{~h}$ in $1 \times \mathrm{PBS}$ and coverslipped using SlowFade Gold mounting media (Invitrogen). It has been previously demonstrated that the GFP expression pattern induced in the CRFR1-GFP BAC transgenic mouse fully recapitulates endogenous CRFR1 expression, but with higher sensitivity (Justice et al., 2008). Hence, immunolabeling of GFP in these transgenic mice will be referred to as "CRFR1-GFP labeling."

Visualization of cochlear innervation and afferent synaptic elements. To visualize afferent fiber innervation to inner hair cells, 2- to 3-month-old $C R F R 1^{+/+}$and $C R F R 1^{-/-}$mice were used. CRFR1 ${ }^{-/-}$mice were born to $C R F R 1^{-/-}$males and CRFR1 ${ }^{+/-}$females. This is significant because CRFR $1^{+/-}$females produce normal levels of glucocorticoids (Smith et al., 1998), and thus any defects observed in CRFR $1^{-/-}$offspring are not the result of loss of glucocorticoid exposure either during in utero development or postnatally (until weaning). Cochleae were processed as described above. For fiber visualization, cochleae were perfused and postfixed with $4 \%$ paraformaldehyde and then decalcified as described above. Following decalcification, whole-mount preps of cochlear middle turns were dissected and incubated in blocking solution as described. Immunofluorescence labeling was performed using goat anti-sodiumpotassium ATPase $\alpha 3$ subunit (NKA) (1:100, Santa Cruz Biotechnology) in $1 \%$ normal donkey serum and $0.1 \%$ Triton $\mathrm{X}-100$ at room temperature overnight. To visualize efferent fiber innervation, cochleae were processed as above, and monoclonal antibodies to synaptophysin (Millipore) were used. All images of whole-mount samples generated for fiber innervation analyses were taken from middle cochlear regions (the primary full turn of the mouse cochlea).

For synaptic ribbon and AMPA receptor immunofluorescence, adult CRFR $1^{+/+}$and CRFR $1^{-/-}$cochleae were perfused with $4 \%$ paraformaldehyde at $4^{\circ} \mathrm{C}$ for $\sim 30 \mathrm{~s}$ to $1 \mathrm{~min}$. The cochleae were then moved to $4^{\circ} \mathrm{C}$ $1 \times$ PBS, and apical cochlear turns were immediately dissected as wholemount samples. The apical pieces were then fixed further in $4 \%$ paraformaldehyde for $20 \mathrm{~min}$ at $4^{\circ} \mathrm{C}$ in an Eppendorf tube. Following fixation, and apical sections were rinsed and incubated in blocking solution (5\% normal donkey serum, $0.5 \%$ Triton $\mathrm{X}-100$ ) for $2 \mathrm{~h}$ at $4^{\circ} \mathrm{C}$ and in primary antibody solution (containing 1\% normal donkey serum, $0.1 \%$ Triton $\mathrm{X}-100$ ) overnight at $4^{\circ} \mathrm{C}$. Primaries were monoclonal mouse anti-CTBP2 (C-terminal binding protein 2) (1:200, BD Biosciences) and polyclonal rabbit anti-GluR4 (glutamate receptor 4) (1:500, Millipore Bioscience 
Research Reagents). After primary incubation, the apical whole-mount sections were washed three times, 20 min each in $1 \times$ PBS at room temperature, and then incubated in secondary antibody mix of goat antimouse Alexa488 and goat anti-rabbit Alexa594 (each 1:200, Invitrogen) in $1 \%$ normal donkey serum and $0.1 \%$ Triton X-100 overnight at $4^{\circ} \mathrm{C}$. Cochlear pieces were then washed in $1 \times$ PBS, and mounted on slides and coverslipped (Slowfade Gold, Invitrogen).

All images were gathered using a Leica TCS SP2 AOBS confocal microscope. Amira software (Visage Imaging) was used to produce YZ projections of confocal $z$-stacks of the sodium-potassium ATPase $\alpha 3$ labeled sections and three-dimensional (3D) representations of synaptic ribbon and GluR4 distributions. The ImageJ (v.1.43u) function "Analyze Particles" was used to count GluR4 puncta and measure the area of each.

\section{Auditory physiology}

CRFR $1^{+/+}$and CRFR $1^{-/-}$mice aged 6-8 weeks and of either sex were used for all physiological procedures. All mice used in these studies were born and housed in an IAC acoustic chamber. Auditory brainstem response (ABR) and $2 \mathrm{f}_{1}-\mathrm{f}_{2}$ distortion product otoacoustic emission (DPOAEs) thresholds were obtained from CRFR $1^{+/+}$and CRFR1 ${ }^{-1-}$ mice with and without glucocorticoid replacement. Mice were anesthetized with a combination of xylazine $\left(20 \mathrm{mg} \mathrm{kg}^{-1}\right.$, i.p. $)$ and ketamine (100 mg kg ${ }^{-1}$, i.p.) Acoustic stimuli were delivered using a custom acoustic assembly consisting of two electrostatic earphones (EC-1, Tucker Davis Technologies) to generate primary tones. A Knowles miniature microphone (EK-3103) was used to record ear canal sound pressure levels for DPOAE assessments. Stimuli were generated digitally (digital I-O board 6052E, National Instruments). Ear canal sound pressure and electrode voltage were amplified and digitally sampled at $20 \mu \mathrm{s}$ for analysis of response amplitudes (digital I-O board 6052E, National Instruments). For ABRs, needle electrodes were inserted at vertex and pinna, with a ground near the tail. Stimuli were $5 \mathrm{~ms}$ tone pips delivered at $35 \mathrm{~s}^{-1}$. At each test frequency, the sound-pressure level was varied in 5 $\mathrm{dB}$ steps. All ABR threshold measures refer specifically to wave 1 only. For DPOAEs, two primary tones $\left(\mathrm{f}_{2} / \mathrm{f}_{1}\right.$ ratio $\left.=1.2\right)$ were presented with $\mathrm{f}_{2}$ level $10 \mathrm{~dB}$ less than $\mathrm{f}_{1}$. A fast Fourier transform was computed and sound pressures extracted at $f_{1}, f_{2}$, and $2 f_{1}-f_{2}$ after spectral averaging. We interpolated the iso-response contours for DPOAEs from the amplitudeversus-level functions. The criterion response for the DP thresholds was a $2 \mathrm{f}_{1}-\mathrm{f}_{2}$ DPOAE of $0 \mathrm{~dB}$ sound pressure level.

\section{Western blot analyses}

All mice used in these studies were born and housed in an IAC acoustic chamber. To ensure that any expression level changes observed in glucocorticoid-inducible proteins could be compared between $C R F R 1^{+/+}$and CRFR $1^{-/-}$mice, CRFR $1^{-/-}$mice were generated from female $C R F R 1^{+/-}$, male $C R F R 1^{-1-}$ breeder pairs. It has been shown that $C R F R 1^{+/-}$females express normal levels of corticosterone (Smith et al., 1998), and thus, glucocorticoid replacement administered to this breeder paradigm ensures that the developing pups experience similar (potentially increased) circulating corticosterone levels. Whole cochlear lysates (three biological replicates unless otherwise noted) were prepared using cochleae from at least three CRFR $1^{+/+}$and CRFR $1^{-/-}$mice aged $6-8$ weeks. Lysates were prepared on ice in buffer containing TPER (Pierce) lysis buffer that was supplemented with protease inhibitor mixture (Pierce). Protein concentrations were estimated using a micro-BCA kit (Pierce), and $65 \mu \mathrm{g}$ of protein was loaded onto a 10\% SDS polyacrylamide gel. Proteins were resolved using SDS-PAGE and transferred to a polyvinylidene difluoride membrane (Bio-Rad). The membrane was blocked with $5 \%$ nonfat dry milk in TBST ( $50 \mathrm{~mm}$ Tris, $150 \mathrm{~mm} \mathrm{NaCl}, \mathrm{pH}$ 7.6, $0.05 \%$ Tween-20) for $1 \mathrm{~h}$ at room temperature. Primary antibodies were diluted into solution containing 5\% nonfat dry milk in TBST and incubated with the membrane overnight at $4^{\circ} \mathrm{C}$. Primary antibodies used were monoclonal mouse anti-glutamine synthetase (1:300, Millipore), polyclonal guinea pig anti-EAAT1 (excitatory amino-acid transporter 1, hereafter referred to as "GLAST") (1:1000, Millipore), and polyclonal rabbit anti-GluR4 (1:1000, Millipore). Either rabbit anti-actin (1:500, Sigma) or mouse anti-GAPDH (Millipore Bioscience Research Reagents) was used as a lane loading control. Following primary antibody incubation, membranes were washed $3 \times 5$ min each with TBST and incubated with HRP-labeled goat anti-rabbit, goat anti-guinea, or goat anti-mouse secondary (1:2000, Jackson ImmunoResearch) for $1 \mathrm{~h}$ at room temperature. Secondary antibodies were diluted into solution containing 5\% nonfat dry milk in TBST. Following secondary incubation, blots were washed $2 \times 10$ min each in distilled water and then $1 \times 5 \mathrm{~min}$ in TBST. Following the TBST wash, blots were rinsed with distilled water and incubated for $5 \mathrm{~min}$ with SuperSignal West Dura Extended Duration ECL Substrate (Pierce). Bands were visualized using a Kodak ImageStation 2000 gel doc system, and densitometry values were obtained using Un-ScanIt software (Silk Scientific). For quantification of GS expression levels under various glucocorticoid rescue conditions, separate blots were generated for each condition: no treatment, vehicle treatment, or corticosterone treatment. Each no treatment and corticosterone treatment blot contained three wild-type biological replicates (lysates from different pools of mice) and three CRFR1 ${ }^{-1-}$ biological replicates, thereby minimizing potential variability associated with handling. The vehicle treatment blots contained two biological replicates for each group. Densitometry values obtained for each biological replicate were averaged over three technical replicates (each pool of lysates was evaluated on three separately run gels). Expression levels were then normalized to loading controls. Data were then analyzed using Prism software to determine statistical significance using a two-tailed, unpaired $t$ test.

\section{Results \\ CRFR1 is expressed in the cochlea and is well situated for both juxtacrine and paracrine interactions with CRF-releasing elements}

CRFR1 mRNA expression has been reported in the cochlea (Vetter et al., 2002). Here, we determined the expression pattern of CRFR1 protein at a cellular resolution by probing for GFP in BAC transgenic mice expressed under control of the CRFR1 promoter (Justice et al., 2008). Endogenous expression patterns of CRFR1 are fully recapitulated in brains of CRFR1-GFP transgenic mice, and expression of the transgene can be detected with superior sensitivity compared with that obtained with standard immunohistochemical detection of endogenous CRFR1 (Justice et al., 2008). Analysis of CRFR1-driven GFP immunofluorescence revealed abundant expression in support cells of the organ of Corti, including border cells immediately adjacent to IHCs and Deiters' cells under outer hair cells (OHCs) (Fig. 1 $A, C$ ). Immunoreactivity was also observed in inner sulcus cells lining the endolymphatic surface of the spiral limbus, Hensen cells and other support cells lateral to the organ of Corti (hereafter termed "lateral support cells"). This pattern of CRFR1-GFP expression puts CRFR1 in direct apposition with cells expressing CRF (Graham et al., 2010). Double-labeling experiments revealed apposition of the CRF-positive IHCs and OHCs with CRFR1-GFP-positive border cells and Deiters' cells, respectively, indicating potential juxtacrine signaling (Fig. $1 B, D$ ). Additionally, several support cell types expressing CRF also expressed CRFR1-GFP, including the inner sulcus cells, Deiters' cells, and lateral support cells, suggesting potential autocrine and paracrine CRFbased signaling between these cells.

\section{An HPA-equivalent signaling system is expressed in the inner ear}

The presence and localization of glucocorticoid receptors in the inner ear have been previously characterized (ten Cate et al., 1992; ten Cate et al., 1993). Given that the cochlea contains both the initiation signal (CRF) (Graham et al., 2010) and the effector (glucocorticoid receptors) (Rarey and Luttge, 1989) of the systemic HPA axis, we hypothesized that the cochlea may possess a local HPA-equivalent signaling system. To investigate this possibility, we used immunolabeling to detect HPA-related molecules, namely POMC (Fig. $2 A-C$ ), ACTH (Fig. $2 D-F$ ), and MC2R (Fig. 
$2 G-I)$, in cochlear cross-sections. Immunolabeling was performed on tissue from CRFR1-GFP mice to enable colabeling with CRFR1-driven GFP and comparison of respective localizations. Low magnification revealed that expression of each of these HPA-related molecules is widespread in the cochlea, including spiral ganglion cells (Fig. 2A,D,G), which also express CRF (Graham et al., 2010). Interestingly, CRFR1-GFP immunolabeling was not found in the spiral ganglion cells (data not shown). Higher magnification of the organ of Corti (Fig. $2 B, E, H$ ) revealed that, while some cells expressed two of the HPA-related molecules, in general POMC (Fig. 2B), ACTH (Fig. 2E), and MC2R (Fig. $2 H$ ) each had a distinct expression pattern. Double labeling results revealed that these molecules were expressed both in proximity to and colocalized with CRFR1-GFP immunopositive cells (Fig. 2C, F, I). POMC and ACTH were detected in the CRFR1-GFP-positive inner sulcus cells and support cells lateral to the organ of Corti (Fig. $2 \mathrm{~A}$, arrows). In the organ of Corti, Deiters' cells most abundantly expressed POMC (Fig. 2 B, arrow), but expressed lower levels of ACTH (Fig. 2E) and almost no MC2R (Fig. $2 H$ ). In contrast, the IHCs possessed lowintensity immunolabeling for POMC, but intense ACTH and MC2R labeling (Fig. $2 E, H)$. In particular, MC2R immunoreactivity exhibited very intense and specific expression in IHCs.

\section{Elimination of CRFR1 elevates auditory thresholds}

Given the widespread expression pattern of CRFR1 (inferred by CRFR1-GFP immunolabeling) and its potential to regulate not only CRFR1-specific signaling but also the activity of a cochlear HPA equivalent signaling system, it is possible that CRFR1 expression and activity is important for inner ear function. Given its overall expression pattern and the known function of the cells involved, we hypothesized that one function of CRFR1 may be to regulate cochlear sensitivity. To verify this hypothesis, we evaluated peripheral auditory function in CRFR $1^{-/-}$mice using two measures. ABR thresholds provide an assessment of acoustic sensitivity, and wave 1 provides information specifically on the summed activity of the cochlear nerve in response to sound stimulation (all ABR data described will refer to wave 1 only). DPOAE isoresponse measures (hereafter termed "DP thresholds," which here are related to a $0 \mathrm{~dB}$ response amplitude) provide an assessment

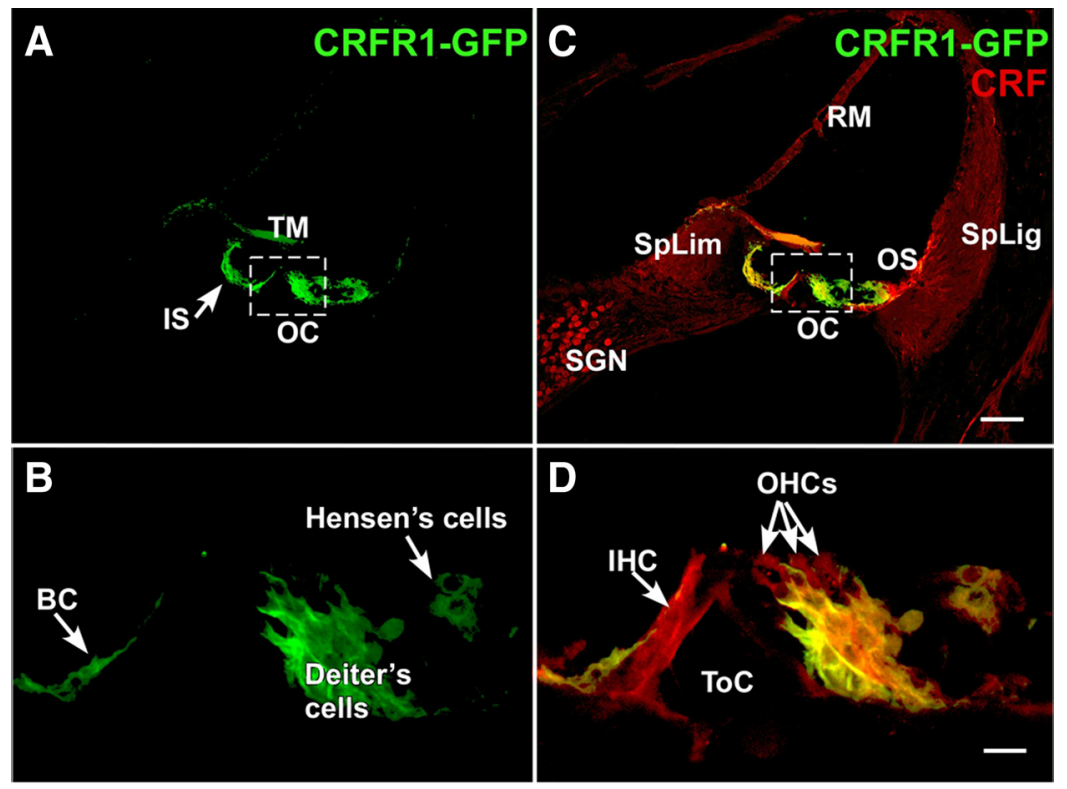

Figure 1. CRFR1 expression overlaps and juxtaposes sites of CRF expression suggesting paracrine and juxtacrine signaling. $\boldsymbol{A}$, Immunofluorescent detection of GFP driven by the CRFR1 promoter demonstrates expression in the inner sulcus (IS) and support cells lateral to the organ of Corti (OC). Intense immunoreactivity is also observed in the organ of Corti (boxed), shown at higher magnification in $\boldsymbol{C}$. B, Double label with CRF reveals regions of overlapping expression (inner sulcus and lateral support cells), suggesting the possibility of paracrine/autocrine signaling. $C$, At higher magnification, intense CRFR1-GFP immunofluorescence is observed in the Deiters' cells and in the border cell (BC). D, Overlay with CRF reveals that these CRFR1-positive cells juxtapose cells expressing CRF, including the IHCs and $\mathrm{OHCS}$ (arrows). TM, Tectorial membrane; SGN, spiral ganglion neurons; SpLim, spiral limbus; OS, outer sulcus; SpLig, spiral ligament; RM, Reissner's membrane; ToC, tunnel of Corti. Scale bars: $C, 60 \mu \mathrm{m} ; \boldsymbol{D}, 10 \mu \mathrm{m}$.
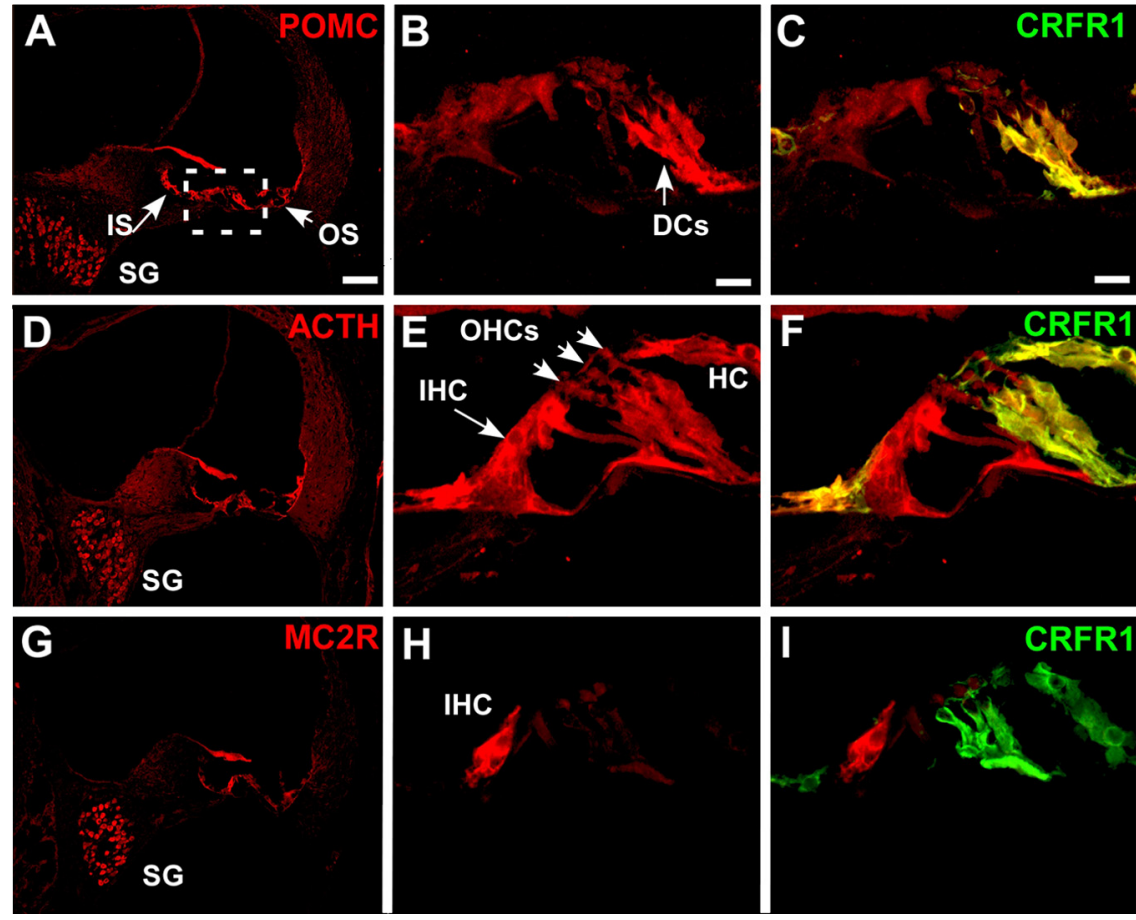

Figure 2. The cochlea expresses an HPA-equivalent signaling system. Immunofluorescent labeling of POMC, ACTH, and MC2R reveals expression of classic HPA components in the cochlea. A, D, G, POMC and ACTH are expressed in inner and outer sulcus cells lining the cochlear duct (IS and OS, respectively). MC2 is expressed in these regions to a lesser extent (C). All components are expressed in the spiral ganglion cells (SG). The organ of Corti region is boxed in $\boldsymbol{A}$ and is the region from which the higher magnification illustrations were produced. $B, C$, Higher magnification of the organ of Corti region reveals intense POMC labeling in the Deiters' cells (DCs) (B), and this expression overlaps with CRFR1-GFP label (C). $\boldsymbol{E}, \boldsymbol{F}$, ACTH shows less immunolabeling in Deiters' cells compared with POMC, but an intense labeling of the IHC. $\boldsymbol{H}, \boldsymbol{I}$, Finally, in the organ of Corti region, MC2R shows an intense and specific labeling for the IHC and a lack of Deiters' cell labeling. Scale bars: $\boldsymbol{A}$ (for $\boldsymbol{A}, \boldsymbol{D}, \boldsymbol{G}), 60 \mu \mathrm{m} ; \boldsymbol{B}$ (for $\boldsymbol{B}, \boldsymbol{C}, \boldsymbol{E}, \boldsymbol{F}, \boldsymbol{H}, \boldsymbol{I}), 10 \mu \mathrm{m}$. HC, Hensen's cell. CRFR1 designates CRFR1-GFP immunolabeling. 

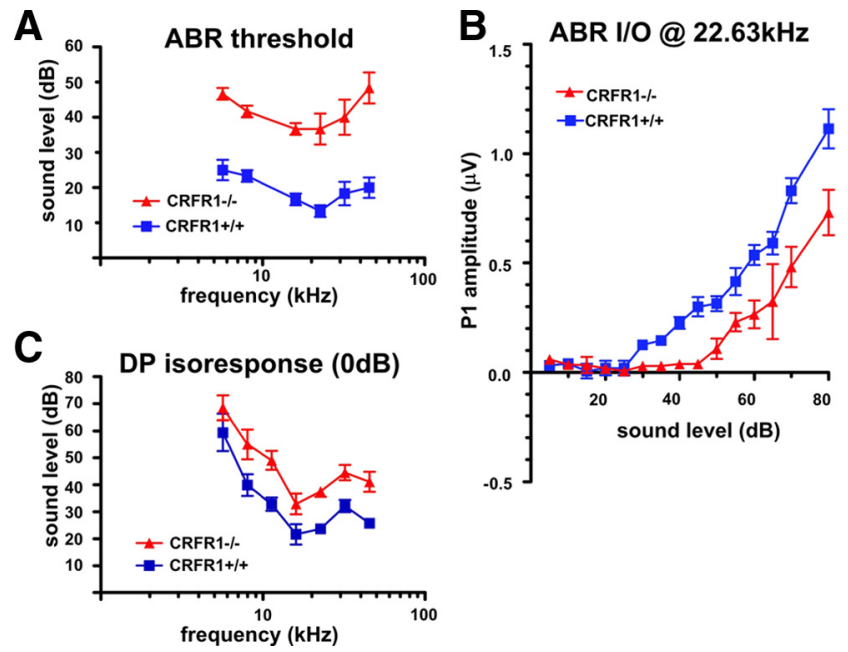

Figure 3. Elimination of CRFR1 causes auditory impairment. $A$, ABR thresholds were measured in wild-type and CRFR $1^{-1-}$ mice. Symbols mark the average threshold observed at each frequency tested $(5.66,8,16,22.65,32,45.25 \mathrm{kHz}) \pm$ SEM. CRFR $1^{-1-}$ mice exhibited a $20-30 \mathrm{~dB}$ increase in ABR thresholds. $\boldsymbol{B}$, The amplitude versus sound level relationship of the $22 \mathrm{kHz}$ wave 1 obtained during $A B R$ analysis was plotted. The loss of sensitivity of $C R F R 1^{-/-}$mice is reflected in the pronounced zero amplitude up to $45 \mathrm{~dB}$ stimulus intensity. Once the $C R F R 1^{-/-}$wave 1 response began to grow, however, the slope of the amplitude growth was identical, although the peak current was $35 \%$ less than that of the CRFR ${ }^{+/+}$mice (two-way ANOVA, $\left.F_{(1,122)}=66.49, p<0.0001\right)$. C, Sound levels required to generate a $2 \mathrm{f1}-\mathrm{f} 2 \mathrm{DPOAE}$ isoresponse to $0 \mathrm{~dB}$ was increased $5-10 \mathrm{~dB}$ in $\mathrm{CRFR}^{-1}$ mice compared with wild-type mice. All error bars are SEM.

of cochlear mechanics, particularly the contribution of the electromotile outer hair cells that may comprise the cellular basis of the cochlear amplifier (Liberman et al., 2002). ABR thresholds were on average $18 \mathrm{~dB}$ higher across all tested frequencies in $C R F R 1^{-/-}$mice compared with wild-type mice, indicating reduced cochlear sensitivity (Fig. 3A). Reduced sensitivity can occur due to changes in neural encoding, abnormal cochlear amplification, and/or changes in the endolymphatic potential (EP), the driving force for cochlear transduction. To begin dissecting the possible mechanisms underlying the elevated ABR thresholds in CRFR $1^{-/-}$mice, we examined the growth rate of $A B R$ responses to tone pips above threshold. Whereas the ABR thresholds provide a measure of cochlear sensitivity, the suprathreshold responses provide a more complete analysis of the inputoutput characteristics of the cochlea and more detailed information regarding how the auditory nerve responds to increasing sound intensities. This information can then be used to help distinguish between different mechanisms underlying cochlear dysfunction. An examination of suprathreshold characteristics of auditory nerve activity (Fig. $3 B$ ) revealed that the CRFR $1^{-/-}$suprathreshold response grew with a statistically similar amplitude-sound level relationship to the $C R F R 1^{+/+}$suprathreshold response (comparing linear regression-generated slopes on nonzero amplitudes, CRFR $1^{+/+}$ $1 /$ slope $=54.05, C R F R 1^{-/-} 1 /$ slope $=48.25 ; F_{(1,75)}=0.418, p=$ $0.520)$. However, the mean peak response of the CRFR1 ${ }^{-1-}$ mice was only $\sim 65 \%$ of the wild-type amplitude, and was statistically different between genotypes (two-way ANOVA, $F_{(1,122)}=66.49$, $p<0.0001)$. DP thresholds were also elevated in CRFR1 ${ }^{-/-}$mice by an average of $9 \mathrm{~dB}$ (Fig. $3 C$ ), which was statistically significant (twoway ANOVA, $\left.F_{(1,70)}=41.91, p<0.0001\right)$, suggesting that potentially impaired OHC motility, the cellular basis for the cochlear amplifier, may contribute to the ABR deficit.

Because the CRFR1 ${ }^{-1-}$ mice exhibited changes in both DP isoresponse thresholds and $\mathrm{ABR}$ thresholds, data were plotted to more directly compare the audiometric (ABR) defects with the

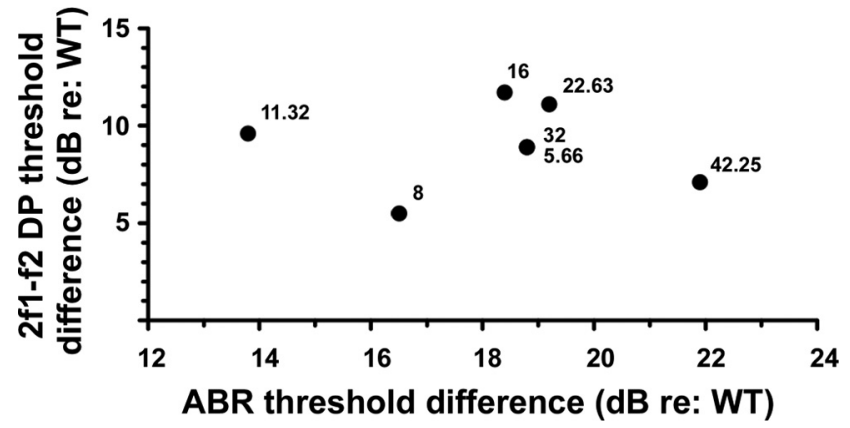

Figure 4. Threshold-threshold plots reveal dynamics of DP and ABR threshold changes induced by loss of CRFR1 expression. To better assess the origins of the ABR threshold shifts observed in CRFR $^{-1-}$ mice, threshold-threshold differences (null threshold values subtracted from wild-type values) were plotted. DP amplitude differences are similar for each tested frequency, but ABR thresholds vary more widely, suggesting that a simple decline in EP and any consequent associated change in cochlear amplifier function cannot explain the entire $A B R$ threshold shift observed. Thus, a mixed neural and EP deficit is indicated as cause for altered ABR thresholds in CRFR1 ${ }^{-/-}$mice. Numbers next to symbols indicate frequency tested. WT, Wild-type.

cochlear amplifier (DP) defects in an attempt to understand the origins of the auditory changes induced by loss of CRFR1 gene expression. A differential threshold-threshold plot of the ABR and DP shifts induced by CRFR1 gene ablation (relative to wildtype results) was generated to more easily assess whether the ABR threshold elevation coincided with a similar DP threshold change (Fig. 4). If ABR thresholds varied constantly with DP thresholds, one would interpret the ABR threshold shift as the consequence of abnormal cochlear amplification. The threshold-threshold plot revealed that the DP difference was relatively constant (average $9 \mathrm{~dB}$ shift range, 5.5-11.7), while the ABR thresholds were twice as high (average $18 \mathrm{~dB}$ shift) with a slightly greater range (13.8-21.9). Comparing these data to those of Mills (2006) suggests that the defects observed may have mixed (neural and EP) origins.

\section{Elimination of CRFR1 disrupts processes important for presynaptic signaling}

One possible explanation for the greater shift in ABR threshold compared with DP threshold is that an afferent (neural) dysfunction contributes to the hearing deficit in $C R F R 1^{-/-}$mice. As described above, CRFR1 expression does not appear in either the IHC or in the spiral ganglion cells where it could directly modulate afferent transduction. However, CRFR1 is expressed in the border cell adjacent to the IHC. This cell is thought to participate in the glutamate-glutamine cycle at the afferent synapse (Ottersen et al., 1998). During this cycle, the border cell clears glutamate from the synaptic cleft, breaks it down to glutamine, and shuttles the glutamine back to the IHC to be resynthesized to glutamate, thereby replenishing the neurotransmitter supply while avoiding potential excitotoxicity. Two key molecules in this process are GLAST, the excitatory amino acid transporter EAAT1 that clears glutamate from the synaptic cleft and transports it into the border cell, and GS, the enzyme that converts glutamate to glutamine. Both of these molecules have been previously demonstrated in cells of the organ of Corti (Eybalin et al., 1996; Furness and Lehre, 1997). To determine whether elimination of CRFR1 disrupts glutamate-glutamine cycling between the border cell and IHC, expression levels of both proteins were examined via Western blot. No changes were observed in GLAST expression levels between wild-type and CRFR1 ${ }^{-/}$mice (Fig. $\left.5 A, C\right)(p=$ $0.3248)$. However, $C R F R 1^{-1-}$ mice exhibited a baseline $50 \%$ reduc- 
tion in GS levels compared with wild-type mice (Fig. $5 B, C)(p=0.0215)$. GS expression is known to be a glucocorticoid-inducible protein, and the GS promoter contains a glucocorticoid response element (Vardimon et al., 1999). Given the role of CRFR1 in inducing glucocorticoid activity via classic systemic HPA signaling, and possibly by the local HPA equivalent signaling system described above, we investigated whether the decreased GS levels in CRFR1 ${ }^{-1-}$ mice resulted from a systemic glucocorticoid deficiency reported in these mice (Smith et al., 1998) by providing an exogenous supply of glucocorticoid. CRFR1 $1^{-/-}$or $C R F R 1^{+/+}$ mice were divided into three groups: mice receiving no treatment, mice administered corticosterone $(0.25 \mathrm{mg} / \mathrm{ml} ; 10 \mathrm{mg} / \mathrm{ml}$ stock solution was prepared in $100 \%$ ethanol), or mice receiving vehicle alone ( $1 \mathrm{ml}$ of $100 \%$ ethanol in $400 \mathrm{ml}$ of water) in their drinking water beginning either at P12 (i.e., before weaning) or in utero throughout gestation. Regardless of when treatment began, the reduction in GS levels persisted in CRFR1 $1^{-/-}$ mice that were untreated or treated with vehicle alone (Fig. $5 B, C)(p=0.0289)$, but was abolished by corticosterone treatment (Fig. $5 B, C)(p=0.616)$.

Corticosterone treatment fails to rescue auditory impairment in $C R F R 1^{-1-}$

mice

CRFR $1^{-1-}$ mice are deficient in systemic glucocorticoids due to abnormal development of the adrenal cortex (Smith et al., 1998). Moreover, our data suggest that a local HPA signaling system potentially controlled by CRFR1 could be disrupted in the cochlea following global constitutive ablation of the CRFR1 gene. Given that reduced GS levels in $C R F R 1^{-1-}$ mice can be rescued by administration of exogenous corticosterone (Smith et al., 1998), we assessed whether corticosterone administration to CRFR1 ${ }^{-1-}$ mice could also rescue their impaired auditory function, and thereby argue for a classic HPA signaling defect as the cause of auditory impairment. Corticosterone was included in the drinking water of pregnant mice (wild-type breeder pairs to give rise to wild-type pups, and knock-out breeder pairs to produce CRFR1 $1^{-1-}$ pups) from E12 onward. The effect of corticosterone replacement on ABR thresholds was then examined in these two populations. Although exogenous corticosterone supplement rescues GS expression levels in CRFR1 ${ }^{-/-}$mice, elevation in ABR thresholds persisted in CRFR1 ${ }^{-1-}$ mice treated with corticosterone (Fig. $6 A$ ). The ABR threshold difference observed between wild-type and CRFR1 $1^{-1-}$ mice was reduced from an average of $18 \mathrm{~dB}$ to an average of $10-15 \mathrm{~dB}$ following corticosterone administration. Interestingly, the apparent reduction in ABR threshold differences following glucocorticoid treatment resulted more from an elevation in wild-type thresholds, rather than a normalization of $C R F R 1^{-1-}$ thresholds. Examination of suprathreshold responses following glucocorticoid administration (Fig. $6 B$ ) revealed an increase in maximal ABR amplitude in CRFR $1^{-1-}$ mice (compare Figs. $3 B, 6 B$ ) to a response equal to that of wild-type mice without treatment. Consistent with the observed $C R F R 1^{+/+}$
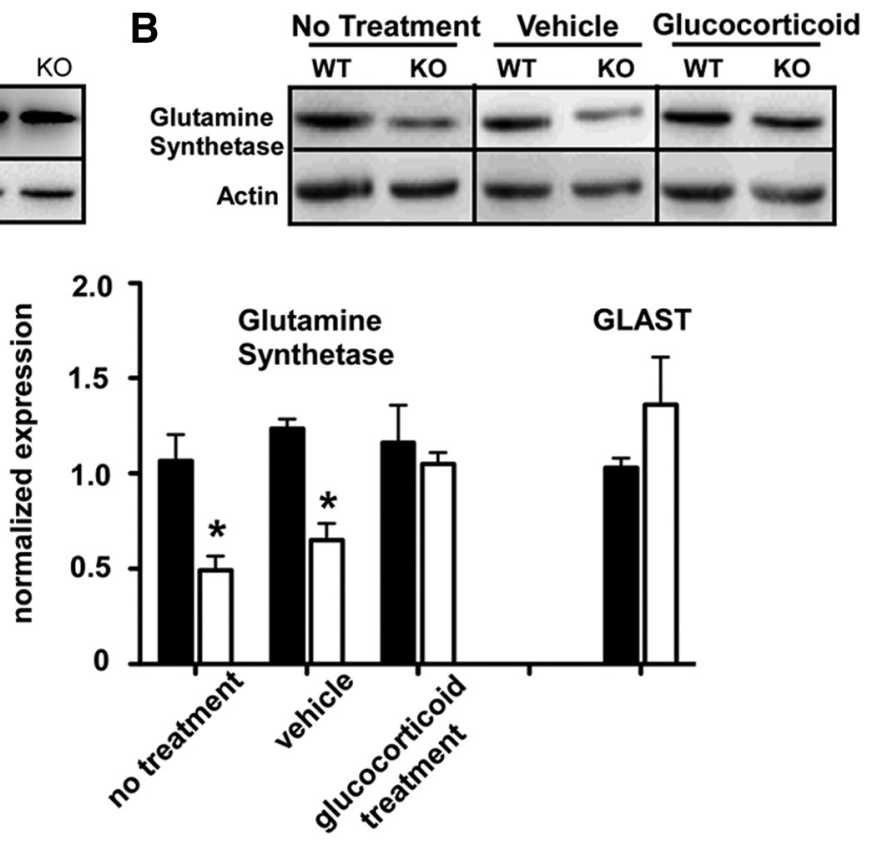

Figure 5. GLAST expression is normal in CRFR $1^{-/-}$mice, while glutamine synthetase levels are reduced in $C R F R 1^{-/-}$mice and rescued by corticosterone treatment. $\boldsymbol{A}$, Western blot analysis of whole cochlear lysates revealed normal levels of GLAST vild-type mice (no treatment) or vehicle treatment $\left(0.25 \%\right.$ ethanol in double distilled $\left.\mathrm{H}_{2} \mathrm{O}\right)$. Glucocorticoid replacement therapy a distration of $0.25 \mathrm{mg} / \mathrm{ml}$ corticosterone (dissolved in $0.25 \%$ ethanol) in the drinking water beginning either at P12 or in

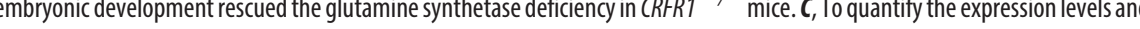
ffects of treatment, Western blot band densities were measured and normalized to lane loading controls. With no treatment, values ( $p=0.616$ ). Despite a trend toward increased GLAST expression, baseline (no treatment) GLAST expression was not significantly different between $C R F R 1^{-/-}$and $C R F R 1^{+/+}$mice $(p=0.3248)$. All error bars are SEM.

ABR threshold elevation following corticosterone administration, suprathreshold amplitudes from wild-type mice treated with corticosterone were slightly reduced. Further analysis will be required to determine the mechanism underlying the effect of corticosterone treatment on wild-type auditory thresholds.

\section{Elimination of CRFR1 results in afferent and efferent innervations defects}

Apposition of IHC presynaptic and postsynaptic elements CRFR $1^{-1}$ mice exhibited significantly elevated ABR thresholds even after exogenous treatment with corticosterone, and when raised under quiet conditions. This suggests that elimination of CRFR1 gene expression causes a perturbation of auditory processing that does not result from systemic glucocorticoid deficiency or noise exposure. We hypothesized that developmentally related structural defects, especially at the afferent synapse, contribute to the hearing loss of CRFR1 $1^{-1-}$ mice. CRFR1 $1^{-1-}$ mice possessed normal numbers of spiral ganglion neurons (see supplemental Fig. 1, available at www.jneurosci.org as supplemental material). IHC afferent presynaptic and postsynaptic structure can be visualized with antibodies to CTBP2 (which caries sequence identical to the C-terminal B-domain of the ribbon-specific protein RIBEYE) to label presynaptic ribbons (Khimich et al., 2005; Schmitz, 2009) and with antibodies to GluR4 to label postsynaptic glutamate receptors (Matsubara et al., 1996). Juxtaposition of presynaptic and postsynaptic structures appeared normal in $C R F R 1^{-1-}$ mice (Fig. $7 A$ ), and there was no difference in synaptic ribbon number between $C R F R 1^{-1-}$ and wild-type mice (two-tailed Mann- 
A

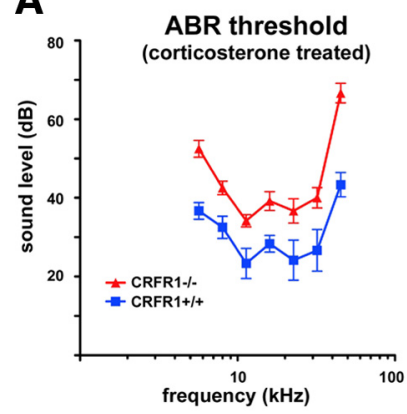

B

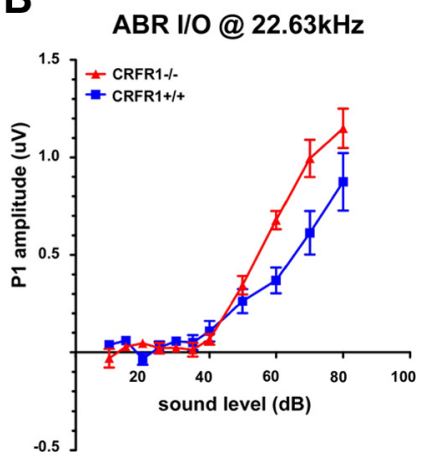

Figure 6. Corticosterone treatment does not rescue auditory function deficits in CRFR1 ${ }^{-/-}$ mice. Timed pregnant $\left(R F R 1^{-/-}\right.$and wild-type mice ( $n=6$ per group) were administered corticosterone $(0.25 \mathrm{mg} / \mathrm{ml})$ in their drinking water begining at E12. Auditory function of the pups was analyzed at 8 weeks of age (with continuous corticosterone treatment after weaning). $A, A B R$ thresholds remained elevated in $C R F R 1^{-/-}$mice (red line) compared with wild-type mice (blue line) by an average of $10-15 \mathrm{~dB}$. Interestingly, the decrease in threshold difference compared with wild types is reflected not in a rescue of the $C R F R 1^{-/-}$ABR thresholds (compare with Fig. 3), but rather an elevation in the wild-type ABR thresholds. $B, A B R$ suprathreshold responses following glucocorticoid administration from the same animals in $A$ reveal that maximal amplitude response of $C R F R 1^{-1-}$ mice is increased to normal levels, while that of wild types decreased to levels similar to that of nontreated $C R F R 1^{-/-}$mice (compare with Fig. $3 B$ ). All error bars are SEM.

Whitney $U$ test, $p=0.482$; data not shown). GluR4 and CTBP2 immunolabeling of the IHCs revealed a tighter packing of the presynaptic and postsynaptic elements in CRFR $1^{-1-}$ mice compared with wild-type mice (Fig. 7A). Three-dimensional reconstruction of the IHC base (nuclear level and below) revealed both an increase in the size of GluR4 immunoreactive regions, and approximately a $60 \%$ increase in the occurrence of at least two ribbons apposed to the same GluR4-labeled profile in the CRFR1 ${ }^{-1}$ mice (Fig. 7A,B). Western blot analysis of GluR4 expression (Fig. $7 C$ ) revealed a significant increase in cochlear expression (two-tailed Mann-Whitney $U$ test, $p=0.0074$ ). Measurement of the GluR4 puncta area in the $x-y$-plane (flattened $z$-plane) (Fig. 7A, orientation illustrated) revealed a bimodal distribution of areas in both wild-type and CRFR1 ${ }^{-1-}$ mice (Fig. $7 D$ ). It is likely that the right-hand modal distribution is related to the larger GluR4 conglomerates observed. While the distribution of GluR4 puncta area of $C R F R 1^{-1-}$ mice mirrored that of the wild-type mice, small puncta were less often observed in CRFR1 ${ }^{-1-}$ mice, while puncta $>0.6 \mu \mathrm{m}^{2}$ were more often observed in the CRFR1 $1^{-1-}$ mice than in the wild types. Thus, the mean size of GluR4 puncta was significantly larger in CRFR $1^{-1-}$ mice compared with wild-type (mean, $0.97 \pm 0.07 \mu \mathrm{m}^{2}$ in CRFR $1^{-/-}$mice; $0.72 \pm 0.05 \mu \mathrm{m}^{2}$ in $C R F R 1^{+/+}$mice; $p=$ 0.0007, Mann-Whitney $U$ test). Furthermore, 3D reconstruction of the confocal $z$-stacks of the IHC afferent synaptic region revealed a paucity of the synaptic ribbons present on the pillar side of the IHC of CRFR1 $1^{-/}$mice (Fig. 7E), a region known to contain fibers primarily associated with high-spontaneous rate, lowthreshold responses in other species (Liberman, 1982; Kawase and Liberman, 1992). This is especially interesting given the ABR threshold elevation observed in the $C R F R 1^{-1-}$ mice noted above.

\section{Afferent fiber innervation to IHCs}

The atypical distribution of synaptic ribbons and GluR puncta observed with $3 \mathrm{D}$ reconstruction of the CRFR1 ${ }^{-/-}$IHC region suggests that targeting of the type 1 afferent fibers to IHCs may also be abnormal. Antibodies to the ATPase $\alpha 3$ subunit are particularly useful for visualizing the entire extent, including the most distal endings, of afferent fibers (McLean et al., 2009). Thus, to investigate afferent fiber innervation in CRFR $1^{-/-}$mice, immunofluorescent labeling of the NKA was performed on whole-mount preparations of the cochlear middle turn. IHCs were visualized using myosin VI immunolabeling. As observed with the ribbon-labeling experiments, $C R F R 1^{-1-}$ mice exhibited reduced IHC modiolar-topillar width (Fig. 8A,C) despite controlling for observation from similar locations along the cochlea. Confocal $x-y$ (flattened $z$-stack) images of double-immunolabeled cochleae revealed fewer fibers extending toward the pillar side of the IHCs in $C R F R 1^{-1-}$ mice, suggesting stunted outgrowth (Fig. 8A,B). The abnormal pillar-side innervation of CRFR $1^{-1-}$ mouse IHCs was more readily revealed by examining the NKA channel alone. Terminal endings of pillar-side fibers in wild-type mice were decorated with abundant NKA puncta (Fig. $8 \mathrm{~B}$, large arrows; Fig. $8 \mathrm{H}$, dashed circle). NKA puncta were absent from the pillar side of IHCs in CRFR $1^{-1-}$ mice (Fig. $8 D$, region above dashed line and arrows; Fig. $8 I$, dashed circle), suggesting lack of afferent fiber endings in this area. Supplemental Figure 2 (available at www.jneurosci.org as supplemental material) further demonstrates the lack of pillar-side innervation. Higher magnification images revealed that fibers followed a direct course toward the IHC in wild-type mice but consistently showed an abnormal clustering of afferent fiber endings before innervation of the IHC region in $C R F R 1^{-1-}$ mice (Fig. 8E, F, boxed region). This abnormal cluster of terminal swellings appears on the modiolar side of the IHC, presumably in the area of Rosenthal's canal, the constricted region through which all afferent fibers must pass to reach the organ of Corti. The $y-z$-axis projections from $C R F R 1^{-1-}$ mice revealed a similar cluster of fibers on the modiolar side of the IHC, most likely corresponding to those observed in the $x-y$ projections (Fig. $7 G$, boxed region). Furthermore, correlated with the ribbon/GluR labeling described above, $y-z$ projections of NKA-labeled fibers revealed diminished innervation on the pillar surface of the IHC in $C R F R 1^{-/}$mice compared with wild-type mice (Fig. 8 H,I, dashed circle regions).

\section{Efferent fiber innervation to $\mathrm{OHCs}$}

Hair cells are not only presynaptic to afferent fibers, but also are targets of descending neural innervation originating from neurons residing in nuclei of the superior olivary complex of the lower brainstem. One portion of the olivocochlear system directly innervates the $\mathrm{OHC}$ soma. The fibers project to the $\mathrm{OHC}$ region via stereotypic tunnel-crossing fibers that are generally displaced high within the tunnel of Corti and maintain a straight trajectory to the OHC region. As demonstrated in Figure 9A, following immunofluorescence labeling for TuJ1 in CRFR $1^{+/+}$ adult mice, the tunnel-crossing fibers are observed to bend just before generating their synaptic endings (Fig. 9A, small arrows). The fibers as well as the terminal endings are arranged in an orderly manner throughout the $\mathrm{OHC}$ region. In adult $C R F R 1^{-1-}$ mice, however, the olivocochlear fibers meandered extensively among the OHCs (Fig. $9 \mathrm{~B}$, arrows) and were often times observed projecting out of the hair cell region to invade lateral support cell areas (Fig. $9 B$, arrowhead). Immunolabeling for synaptophysin revealed the efferent boutons under the OHCs (Fig. 9C,D). As described for wild-type mice previously (Vetter et al., 1999, 2007), OHCs were contacted by two to three efferent boutons in CRFR $1^{+/+}$mice (Fig. 9C, arrows). However, in CRFR $1^{-/-}$mice, OHCs were hyperinnervated by efferent boutons, often times being contacted by three to five terminals (Fig. 9D, arrows). Additionally, unusual aggregates of bouton clusters were observed (Fig. 9D, dashed circles) despite the OHCs being normally distributed (data not shown) within the region. The number of ef- 
ferent synaptic terminals innervating each row of OHCs was counted along the main cochlear turn (mid-frequency regions) in CRFR $1^{+/+}$and CRFR1 $1^{-/-}$mice (117 hair cells examined in CRFR $1^{+/+}$and 121 hair cells examined in CRFR $1^{-/-}$mice) and plotted as the percentage of total observations (Fig. 9E). The results confirmed that CRFR $1^{-1-}$ OHCs are contacted by more efferent terminals than are the OHCs of CRFR $1^{+/+}$mice (two-tailed Student's $t$ test, $p=0.0063$ ). These anomalies were present throughout the cochlea and were not more often seen in any one region. Thus, just as described for afferent innervation, significant defects to efferent innervation were observed following the loss of CRFR1 expression.

\section{Discussion}

\section{Cochlear HPA-equivalent signaling}

Studies of human skin have revealed expression of a local HPA-equivalent signaling system, which, when activated by cellular stress, leads to local synthesis and release of cortisol independent of systemic HPA signaling and adrenal activity (Ito et al., 2005). While our GS data reported here and data in previously published reports (Tahera et al., 2007) indicate that systemic corticosterone can impact cochlear processing, our data suggest that the cochlear HPA-equivalent system may act independent of, or perhaps at times in concert with, the classic HPA axis. An unresolved question is whether the cochlear HPA equivalent system is capable of glucocorticoid synthesis and release. Aldosterone synthase, involved in synthesizing mineralocorticoids, was detected in the cochlea, but 11- $\beta$-hydroxylase, an enzyme responsible for corticosterone production was not (Lecain et al., 2003). However, aldosterone synthase converts deoxycorticosterone to aldosterone in a twostep reaction involving intermediate production of corticosterone, thus suggesting at least low levels of expression in the cochlea. Additionally, glucocorticoid synthesis as an end product may not be the sole function of cochlear HPA-equivalent signaling via MC2R activation. MC2R-based signaling along the classic HPA axis also has glucocorticoid-independent effects and is known to modulate $\mathrm{Ca}^{2+}$ - and voltagesensitive $\mathrm{K}^{+}$(BK) channels (Brunton et al., 2007). This is particularly intriguing given the abundant expression of MC2R in IHCs and the role of $\mathrm{BK}$ in shaping the activity of the IHC, and thus the afferent response to sound (Fettiplace and Fuchs, 1999; Oliver et al., 2006).

Our results show coexpression of CRFR1, POMC, and ACTH in cells of the cochlea. However, discontinuities in the expected

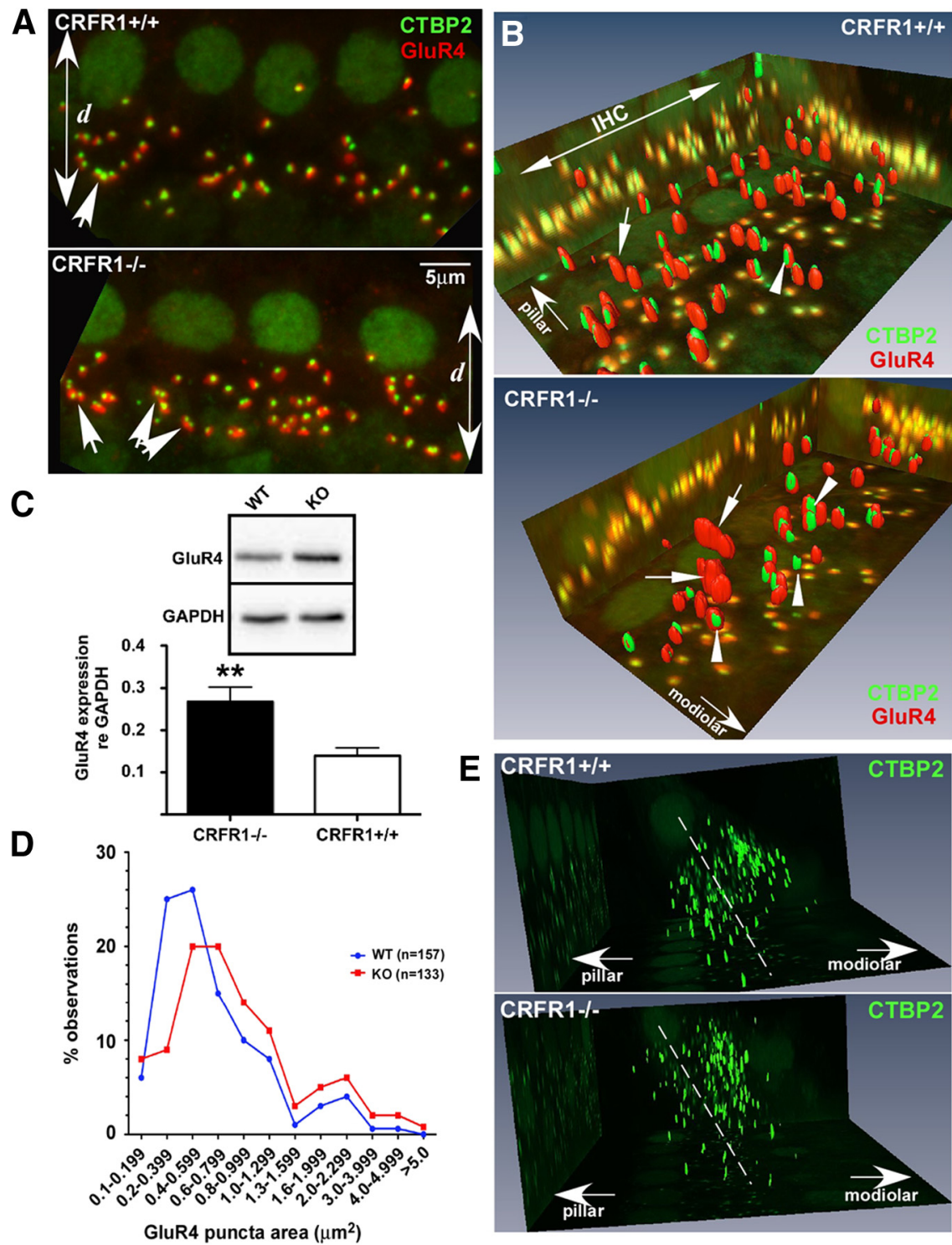

Figure 7. CRFR $1^{-1-}$ mice possess normal numbers of afferent synapses but abnormal synapse distribution. $\boldsymbol{A}$, Presynaptic ribbons and postsynaptic terminals were localized on the inner hair cell by double immunolabeling for CTBP2 (green), a maker for synaptic ribbons in hair cells, and GluR4 (red). While a coincident overlay of ribbons and GluR immunopositive puncta was present in both CRFR $1^{+/+}$and CRFR1 ${ }^{-/}$mice, GluR4 puncta appeared larger in CRFR1 ${ }^{-/}$mice. Additionally, GluR4 puncta were more often apposed to two CTBP2 (synaptic ribbon) puncta in the CRFR ${ }^{-/-}$mice (arrows) compared with CRFR $1^{+/+}$mice. The distance between the nucleus and the edge of the synaptic zone (d) was shorter in (RFR1 ${ }^{-1-}$ mice compared with wild-type mice, generating a tighter clustering of GluR4/CTBP2 ensembles compared with wild-type mice. Scale bar, $5 \mu \mathrm{m}$. $\boldsymbol{B}$, Three-dimensional reconstruction of the basal region of IHCs following double labeling for GluR4 (red) and CTBP2 (green). Large aggregations of GluR4 puncta (arrows) were present in CRFR1 ${ }^{-/}$micethat were only occasionally observed in wild-type mice. Space-filling reconstructions allowed better visualization of doubled ribbon structures (arrowheads) in CRFR1 ${ }^{-1-}$ mice. These were often discerned from simple large ribbons by contours representing the upper and lower limits of the individual ribbons in the aggregate. By contrast, very few double ribbons were observed in wild-type mice (e.g., $A$, arrow). Few GluR4/CTBP2 profiles were observed on the pillar side of the IHC nuclei in CRFR1 ${ }^{-1-}$ mice. C, Western blot of cochlear samples revealed a significant increase in GluR4 expression in CRFR $1^{-/-}$mice compared with CRFR $1^{+/+}$mice $\left({ }^{* *} p=0.0074\right.$, error bars are SEM). $\boldsymbol{D}$, Measurement of GluR4 puncta in the $x-y$-plane revealed a bimodal distribution of GluR4 puncta size in both CRFR ${ }^{+/+}$(blue) and

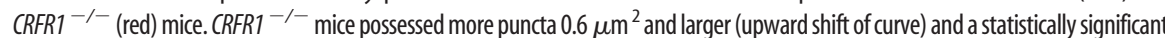
increase in mean puncta size ( $p=0.0007)$. $\boldsymbol{E}$, Three-dimensional analysis revealed an abnormal synaptic ribbon distribution in the CRFR1 ${ }^{-1-}$ mice (right), with more ribbons clustered toward the modiolar side of the hair cell in $C R F R 1^{-1-}$ mice and fewer falling on the pillar side compared with wild type (right). WT, Wild-type; KO, knock-out.

expression pattern (based on expression patterns along the classic HPA axis) occur as well, which may result from several factors. High levels of ACTH and MC2R with little to no POMC, such as occurs in IHCs, may indicate high rates of POMC cleavage by prohormone convertase 1 and 2 , which are responsible for 

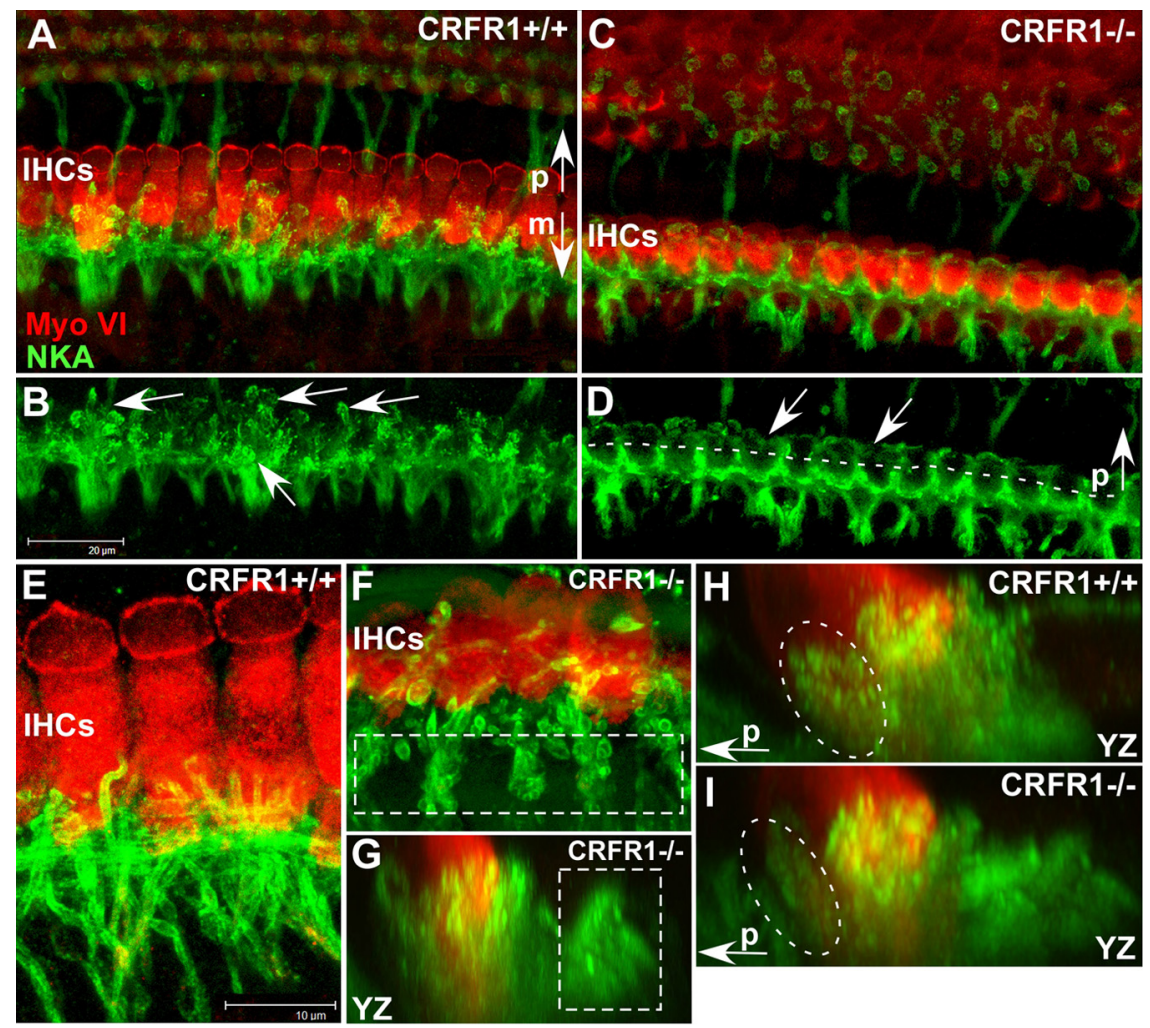

Figure 8. Elimination of CRFR1 causes abnormal afferent fiber innervation. Afferent fibers and their most distal endings were visualized using antibodies directed against NKA (green). IHCs were immunolabeled using antibodies against myosin VI (red). $\boldsymbol{A}-\boldsymbol{D}$, Whole-mount sections of cochlear middle turns were imaged in $C R F R 1^{+/+}(A, B)$ and $C R F R 1^{-1-}(C, D)$ mice. $A, C$ Significant differences in hair cell width [modiolar (m) to pillar (p) along the $y$-axis] are evident. $\boldsymbol{B}, \boldsymbol{D}$, Afferent fiber endings were found on all sides of the IHCs in CRFR ${ }^{+/+}$mice and were decorated with immunoreactive puncta that outlined the termination of the fibers (arrows). These fibers appeared stunted in CRFR ${ }^{-1-}$ mice, with few endings reaching toward the pillar side of the inner hair cell (above dashed line, arrows), and none exhibiting the immunoreactive puncta observed in $\boldsymbol{B}$. $\boldsymbol{E}-\boldsymbol{G}$, An abnormal cluster of fibers was found on the modiolar side of the IHCS of $C R F R 1^{-/-}$mice $\left(\boldsymbol{F}\right.$, dashed box) that is not present in $C R F R 1^{+/+}$ mice $(\boldsymbol{E})$. YZ projections highlight this abnormal clustering in $\left(R F R 1^{-1-}\right.$ mice ( $\boldsymbol{G}$, boxed region). $\boldsymbol{H}, \boldsymbol{I}$, YZ projections also revealed reduced innervation on the pillar surface of the IHC in $C R F R 1^{-/-}$mice $(I)$ compared with $C R F R 1^{+/+}$mice $(H)$ (dashed ovals).

for a multifaceted origin. While elevated DP thresholds indicate suboptimal cochlear amplifier function, the small change ( $9 \mathrm{~dB}$ average) may only partially explain the larger ABR threshold shift. Models suggest that mild-to-moderate ABR deficits (e.g., those exhibited by the CRFR $1^{-1-}$ mice) that are purely the result of cochlear amplifier disruption (and therefore involve only $\mathrm{OHCs}$ ) produce a 1:1 change in ABR thresholds (Mills, 1997). This does not fit our data (Fig. 4). However, if the EP, the driving force over hair cell transduction, were involved in altered cochlear sensitivity, one would expect elevation of both $\mathrm{DP}$ and $\mathrm{ABR}$ thresholds. With a decline in EP, the ABR threshold elevation should be larger than that of the DP as a result of the additive effects of lower EPs (lesser transduction driving forces on all hair cells) plus less robust cochlear amplifier function. In general, this fits our data. However, a number of observations indicate the potential for a mixed neural and EP defect in the CRFR1 ${ }^{-/-}$mice, rather than solely an EP source. First, the average ABR threshold shift was approximately twice that of the DP threshold shift, more than the 1 $\mathrm{dB} / \mathrm{mV}$ shift expected (at high frequencies at least) from a purely EP-derived dysfunction (Sewell, 1984b; Schmiedt et al., 2002). Second, with a pure EP defect, a strong correlation between EP decline and ABR shifts at high frequencies that tails off at lower frequencies is expected. Data from furosemide-treated gerbils (decreasing EPs) demonstrate a constant lowfrequency shift in threshold coupled with

POMC proteolytic processing (Lugo and Pintar, 1996; Stevens and White, 2010). Additionally, POMC can be secreted (Stevens and White, 2010) and cleaved extracellularly (König et al., 2006). The presence of POMC, ACTH, and MC2R in the spiral ganglion neurons in the absence of CRFR1 expression is intriguing. Our previous work (Graham et al., 2010) demonstrated CRFR2 in spiral ganglion neurons. While CRFR1 activation is well known to modulate POMC expression, it has recently been shown that CRFR2 can also stimulate POMC gene expression (Chen et al., 2010). Urocortin, a CRF-related peptide, activates CRFR2 and is expressed in lateral olivocochlear terminals (Vetter et al., 2002), which contact the type 1 afferent fibers. Therefore, urocortin released from lateral olivocochlear terminals could stimulate CRFR2 on the postsynaptic afferent fibers to induce POMC expression and ACTH production. The expression of the ACTH receptor MC2R by IHCs may represent a mechanism by which lateral olivocochlear system input to spiral ganglion cells retrogradely influences IHC function.

\section{Loss of CRFR1 activity induces mixed source} cochlear dysfunction

Our data revealed dysfunctional cochlear activity that included a large ABR threshold elevation coupled with a modest but statistically significant DP threshold change, which combined argues an increasingly severe loss at high frequencies following decline in EP (Schmiedt et al., 2002). Our data indicate no such constant change in ABR thresholds over the frequencies tested (Fig. 4). Third, while our suprathreshold ABR data indicate a lower maximal ABR amplitude, as has been shown to occur following furosemide application (Schmiedt et al., 2002), the growth rate of the neural response is normal once threshold is attained. Normally, a decline in EP induces a significant change in the growth rate (i.e., slope) of the neural response (Schmiedt et al., 2002). Last, our inability to localize CRFR1-GFP expression within the strial compartment or in the spiral ligament (Fig. 1) suggests that strial dysfunction, as a direct result of loss of CRFR1 signaling, likely cannot explain the functional changes observed. But, CRFR1 expression within other support cells, many of which have been suggested to be involved in potassium recycling, suggests further evaluation of this issue is warranted. In sum, our data point to a mixed $\mathrm{EP} /$ neural defect as a mechanism underlying the functional defects observed.

\section{Lack of CRFR1 alters hair cell innervation}

Experiments in the cerebellum and hippocampus have shown that CRFR1 regulates dendritic length, branching, and spine density independent of systemic glucocorticoids (Chen et al., 2004, 2008; Swinny et al., 2004). Loss of CRFR1 results in exuberant dendritic 
outgrowth of hippocampal neurons (Chen et al., 2004). Our results illustrate a developmental, glucocorticoid-independent role for CRFR1 in shaping the structure of afferent and efferent innervation in the cochlea. Major afferent defects were observed in $C R F R 1^{-/-}$mice that persisted in pups born to heterozygous females, which produce normal levels of corticosterone (Smith et al., 1998). First, afferent synapses on IHCs were skewed toward the modiolar side of the cell in $C R F R 1^{-/-}$mice. The position of an afferent terminal along the modiolar versus pillar side of the IHC has been shown to underlie differences in fiber activity in all species investigated. While the definitive experiments have only been performed in the cat (Liberman, 1982; Kawase and Liberman, 1992), evidence also exists in the mouse (Francis et al., 2004; Taberner and Liberman, 2005) and guinea pig (Hashimoto et al., 1990) that low-spontaneous rate, high-threshold fibers tend to synapse on the modiolar side of the IHC, and highspontaneous rate, low-threshold fibers synapse on the pillar side (Liberman, 1982; Kawase and Liberman, 1992). Therefore, the paucity of pillar-side fibers in the distribution of afferent synapses in CRFR $1^{-/-}$ mice may indicate a plastic change in afferent fiber population toward low-spontaneous rate, high-threshold synapses in these mice, and could partially explain their elevated $A B R$ thresholds. Interestingly, the size and complexity of synaptic ribbons are known to increase with decreasing spontaneous rate such that larger ribbons and even ribbon doublets are found at low-spontaneous rate, high-threshold synapses (Merchan-Perez and Liberman, 1996). A greater frequency of double ribbons apposed to single postsynaptic GluR clusters was observed in CRFR1 ${ }^{-/-}$mice compared with wild-type mice, further suggesting a skewing toward low-spontaneous rate, high-threshold synapses. Interestingly, lower EPs significantly suppress spontaneous activity rates in hair cells (Sewell, 1984a). Whether constitutively lower EPs induce afferent fiber plasticity during development is intriguing but not directly addressed by our data. In addition to changes in presynaptic structure, we observed increases in the size of GluR4 clusters that are consistent with the higher expression of GluR4 in CRFR1 $1^{-/-}$mice observed through Western blot analysis of cochlear lysates. The absence of CRFR1 expression in spiral ganglion cells suggests that it does not exert a direct effect on GluR4 expression and trafficking. Finally, abnormal clustering of ribbons, likely the result of decreased modiolar-pillar axis width of the IHCs observed in the CRFR $1^{-/-}$mice, may lead to a disruption of afferent activity. Each ribbon responds to local calcium influx mediated by neighboring calcium channels (Meyer et al., 2009). Abnormal spatial distribution of synaptic ribbons may disrupt the normally tight coupling between local calcium influx and release of transmitter from individual ribbons, resulting in decreased ABR thresholds. These findings suggest a trophic role for CRFR1, underscoring its importance in cochlear development. Interestingly, previous work (Zbytek et al., 2005) described a role for CRF signaling in keratinocyte differentiation, inducing the cells to become larger.

In summary, the work presented here demonstrates for the first time the existence of a complete HPA-equivalent signaling system wholly resident within the cochlea that may embody a local cochlear stress response system capable of functioning independent of the classic HPA-based stress axis and systemically derived glucocorticoids. The data indicate that ablation of CRFR1 results in elevation of auditory thresholds. Interestingly, ablation of CRFR2 results in cochlear hypersensitivity (Graham et al., 2010). These combined results suggest that cochlear CRF (and more generally cochlear HPA-equivalent) signaling has a major role in setting cochlear sensitivity and maintaining cochlear homeostasis. Our data further highlight an important developmental role for CRFR1 signaling in afferent synapse distribution. The defects observed following loss of CRFR1 expression highlights its pleiotropic roles in the cochlea. Given that genetic variants of CRFR1 exert strong pharmacogenetic effects that influence therapeutic outcomes [e.g., the response of asthmatic (Tantisira et al., 2004) and COPD (Kim et al., 2009) patients to corticosteroid therapy], future evaluation of CRFR1 activity in auditory processing and the potential for CRFR1 splice variants (Zmijewski and Slominski, 2009, 2010) and/or SNPs (Barr et al., 2009) to alter auditory function and response to therapy are indicated. 


\section{References}

Barr CS, Dvoskin RL, Gupte M, Sommer W, Sun H, Schwandt ML, Lindell SG, Kasckow JW, Suomi SJ, Goldman D, Higley JD, Heilig M (2009) Functional CRH variation increases stress-induced alcohol consumption in primates. Proc Natl Acad Sci U S A 106:14593-14598.

Brunton PJ, Sausbier M, Wietzorrek G, Sausbier U, Knaus HG, Russell JA, Ruth P, Shipston MJ (2007) Hypothalamic-pituitary-adrenal axis hyporesponsiveness to restraint stress in mice deficient for large-conductance calcium- and voltage-activated potassium (BK) channels. Endocrinology 148:5496-5506.

Chen P, Vaughan J, Donaldson C, Vale W, Li C (2010) Injection of Urocortin 3 into the ventromedial hypothalamus modulates feeding, blood glucose levels, and hypothalamic POMC gene expression but not the HPA axis. Am J Physiol Endocrinol Metab 298:E337-E345.

Chen Y, Bender RA, Brunson KL, Pomper JK, Grigoriadis DE, Wurst W, Baram TZ (2004) Modulation of dendritic differentiation by corticotropin-releasing factor in the developing hippocampus. Proc Natl Acad Sci U S A 101:15782-15787.

Chen Y, Dubé CM, Rice CJ, Baram TZ (2008) Rapid loss of dendritic spines after stress involves derangement of spine dynamics by corticotropinreleasing hormone. J Neurosci 28:2903-2911.

Eybalin M, Norenberg MD, Renard N (1996) Glutamine synthetase and glutamate metabolism in the guinea pig cochlea. Hear Res 101:93-101.

Fettiplace R, Fuchs PA (1999) Mechanisms of hair cell tuning. Annu Rev Physiol 61:809-834.

Francis HW, Rivas A, Lehar M, Ryugo DK (2004) Two types of afferent terminals innervate cochlear inner hair cells in C57BL/6J mice. Brain Res 1016:182-194.

Furness DN, Lehre KP (1997) Immunocytochemical localization of a highaffinity glutamate-aspartate transporter, GLAST, in the rat and guineapig cochlea. Eur J Neurosci 9:1961-1969.

Graham CE, Basappa J, Vetter DE (2010) A corticotropin-releasing factor system expressed in the cochlea modulates hearing sensitivity and protects against noise-induced hearing loss. Neurobiol Dis 38:246-258.

Hashimoto S, Kimura RS, Takasaka T (1990) Computer-aided threedimensional reconstruction of the inner hair cells and their nerve endings in the guinea pig cochlea. Acta Otolaryngol 109:228-234.

Henkin RI, McGlone RE, Daly R, Bartter FC (1967) Studies on auditory thresholds in normal man and in patients with adrenal cortical insufficiency: the role of adrenal cortical steroids. J Clin Invest 46:429-435.

Ito N, Ito T, Kromminga A, Bettermann A, Takigawa M, Kees F, Straub RH, Paus R (2005) Human hair follicles display a functional equivalent of the hypothalamic-pituitary-adrenal axis and synthesize cortisol. FASEB J 19:1332-1334.

Justice NJ, Yuan ZF, Sawchenko PE, Vale W (2008) Type 1 corticotropinreleasing factor receptor expression reported in BAC transgenic mice: implications for reconciling ligand-receptor mismatch in the central corticotropin-releasing factor system. J Comp Neurol 511:479-496.

Kawase T, Liberman MC (1992) Spatial organization of the auditory nerve according to spontaneous discharge rate. J Comp Neurol 319:312-318.

Khimich D, Nouvian R, Pujol R, Tom Dieck S, Egner A, Gundelfinger ED, Moser T (2005) Hair cell synaptic ribbons are essential for synchronous auditory signalling. Nature 434:889-894.

Kim WJ, Sheen SS, Kim TH, Huh JW, Lee JH, Kim EK, Lee SM, Lee S, Lim SY, Shin TR, Yoon HI, Oh YM, Lee SD (2009) Association between CRHR1 polymorphism and improved lung function in response to inhaled corticosteroid in patients with COPD. Respirology 14:260-263.

König S, Luger TA, Scholzen TE (2006) Monitoring neuropeptide-specific proteases: processing of the proopiomelanocortin peptides adrenocorticotropin and alpha-melanocyte-stimulating hormone in the skin. Exp Dermatol 15:751-761.

Lecain E, Yang TH, Tran Ba Huy P (2003) Steroidogenic enzyme expression in the rat cochlea. Acta Otolaryngol 123:187-191.

Liberman MC (1982) Single-neuron labeling in the cat auditory nerve. Science 216:1239-1241.

Liberman MC, Gao J, He DZ, Wu X, Jia S, Zuo J (2002) Prestin is required for electromotility of the outer hair cell and for the cochlear amplifier. Nature 419:300-304.

Lugo DI, Pintar JE (1996) Ontogeny of basal and regulated secretion from POMC cells of the developing anterior lobe of the rat pituitary gland. Dev Biol 173:95-109.

Matsubara A, Laake JH, Davanger S, Usami S, Ottersen OP (1996) Organi- zation of AMPA receptor subunits at a glutamate synapse: a quantitative immunogold analysis of hair cell synapses in the rat organ of Corti. J Neurosci 16:4457-4467.

McLean WJ, Smith KA, Glowatzki E, Pyott SJ (2009) Distribution of the $\mathrm{Na}, \mathrm{K}-\mathrm{ATP}$ ase alpha subunit in the rat spiral ganglion and organ of corti. J Assoc Res Otolaryngol 10:37-49.

Merchan-Perez A, Liberman MC (1996) Ultrastructural differences among afferent synapses on cochlear hair cells: correlations with spontaneous discharge rate. J Comp Neurol 371:208-221.

Meyer AC, Frank T, Khimich D, Hoch G, Riedel D, Chapochnikov NM, Yarin YM, Harke B, Hell SW, Egner A, Moser T (2009) Tuning of synapse number, structure and function in the cochlea. Nat Neurosci 12:444-453.

Mills DM (1997) Interpretation of distortion product otoacoustic emission measurements. I. Two stimulus tones. J Acoust Soc Am 102:413-429.

Mills DM (2006) Determining the cause of hearing loss: differential diagnosis using a comparison of audiometric and otoacoustic emission responses. Ear Hear 27:508-525.

Oliver D, Taberner AM, Thurm H, Sausbier M, Arntz C, Ruth P, Fakler B, Liberman MC (2006) The role of BKCa channels in electrical signal encoding in the mammalian auditory periphery. J Neurosci 26:6181-6189.

Ottersen OP, Takumi Y, Matsubara A, Landsend AS, Laake JH, Usami S (1998) Molecular organization of a type of peripheral glutamate synapse: the afferent synapses of hair cells in the inner ear. Prog Neurobiol 54:127-148.

Powers WH (1972) Metabolic aspects of Meniere's disease. Laryngoscope 82:1716-1725.

Rarey KE, Luttge WG (1989) Presence of type I and type II/IB receptors for adrenocorticosteroid hormones in the inner ear. Hear Res 41:217-221.

Schmiedt RA, Lang H, Okamura HO, Schulte BA (2002) Effects of furosemide applied chronically to the round window: a model of metabolic presbyacusis. J Neurosci 22:9643-9650.

Schmitz F (2009) The making of synaptic ribbons: how they are built and what they do. Neuroscientist 15:611-624.

Sewell WF (1984a) The relation between the endocochlear potential and spontaneous activity in auditory nerve fibres of the cat. J Physiol 347:685-696.

Sewell WF (1984b) The effects of furosemide on the endocochlear potential and auditory-nerve fiber tuning curves in cats. Hear Res 14:305-314.

Siaud P, Maurel D, Lucciano M, Kosa E, Cazals Y (2006) Enhanced cochlear acoustic sensitivity and susceptibility to endotoxin are induced by adrenalectomy and reversed by corticosterone supplementation in rat. Eur J Neurosci 24:3365-3371.

Slominski AT, Botchkarev V, Choudhry M, Fazal N, Fechner K, Furkert J, Krause E, Roloff B, Sayeed M, Wei E, Zbytek B, Zipper J, Wortsman J, Paus R (1999) Cutaneous expression of CRH and CRH-R. Is there a "skin stress response system?" Ann NY Acad Sci 885:287-311.

Smith GW, Aubry JM, Dellu F, Contarino A, Bilezikjian LM, Gold LH, Chen R, Marchuk Y, Hauser C, Bentley CA, Sawchenko PE, Koob GF, Vale W, Lee KF (1998) Corticotropin releasing factor receptor 1-deficient mice display decreased anxiety, impaired stress response, and aberrant neuroendocrine development. Neuron 20:1093-1102.

Stevens A, White A (2010) ACTH: cellular peptide hormone synthesis and secretory pathways. Results Probl Cell Differ 50:63-84.

Swinny JD, Metzger F, IJkema-Paassen J, Gounko NV, Gramsbergen A, van der Want JJ (2004) Corticotropin-releasing factor and urocortin differentially modulate rat Purkinje cell dendritic outgrowth and differentiation in vitro. Eur J Neurosci 19:1749-1758.

Taberner AM, Liberman MC (2005) Response properties of single auditory nerve fibers in the mouse. J Neurophysiol 93:557-569.

Tahera Y, Meltser I, Johansson P, Salman H, Canlon B (2007) Sound conditioning protects hearing by activating the hypothalamic-pituitaryadrenal axis. Neurobiol Dis 25:189-197.

Tantisira KG, Lake S, Silverman ES, Palmer LJ, Lazarus R, Silverman EK, Liggett SB, Gelfand EW, Rosenwasser LJ, Richter B, Israel E, Wechsler M, Gabriel S, Altshuler D, Lander E, Drazen J, Weiss ST (2004) Corticosteroid pharmacogenetics: association of sequence variants in CRHR1 with improved lung function in asthmatics treated with inhaled corticosteroids. Hum Mol Genet 13:1353-1359.

ten Cate WJ, Curtis LM, Rarey KE (1992) Immunochemical detection of glucocorticoid receptors within rat cochlear and vestibular tissues. Hear Res 60:199-204.

ten Cate WJ, Curtis LM, Small GM, Rarey KE (1993) Localization of glu- 
cocorticoid receptors and glucocorticoid receptor mRNAs in the rat cochlea. Laryngoscope 103:865-871.

Vardimon L, Ben-Dror I, Avisar N, Oren A, Shiftan L (1999) Glucocorticoid control of glial gene expression. J Neurobiol 40:513-527.

Vetter DE, Liberman MC, Mann J, Barhanin J, Boulter J, Brown MC, SaffioteKolman J, Heinemann SF, Elgoyhen AB (1999) Role of alpha9 nicotinic ACh receptor subunits in the development and function of cochlear efferent innervation. Neuron 23:93-103.

Vetter DE, Katz E, Maison SF, Taranda J, Turcan S, Ballestero J, Liberman MC, Elgoyhen AB, Boulter J (2007) The alpha10 nicotinic acetylcholine receptor subunit is required for normal synaptic function and integrity of the olivocochlear system. Proc Natl Acad Sci U S A 104:20594-20599.

Vetter DE, Li C, Zhao L, Contarino A, Liberman MC, Smith GW, Marchuk Y, Koob GF, Heinemann SF, Vale W, Lee KF (2002) Urocortin-deficient mice show hearing impairment and increased anxiety-like behavior. Nat Genet 31:363-369.
Wang Y, Liberman MC (2002) Restraint stress and protection from acoustic injury in mice. Hear Res 165:96-102.

Yamasoba T, Dolan DF, Miller JM (1999) Acquired resistance to acoustic trauma by sound conditioning is primarily mediated by changes restricted to the cochlea, not by systemic responses. Hear Res 127:31-40.

Zbytek B, Pikula M, Slominski RM, Mysliwski A, Wei E, Wortsman J, Slominski AT (2005) Corticotropin-releasing hormone triggers differentiation in HaCaT keratinocytes. Br J Dermatol 152:474-480.

Zmijewski MA, Slominski AT (2009) CRF1 receptor splicing in epidermal keratinocytes: potential biological role and environmental regulations. J Cell Physiol 218:593-602.

Zmijewski MA, Slominski AT (2010) Emerging role of alternative splicing of CRF1 receptor in CRF signaling. Acta Biochim Pol 57:1-13.

Zmijewski MA, Sharma RK, Slominski AT (2007) Expression of molecular equivalent of hypothalamic-pituitary-adrenal axis in adult retinal pigment epithelium. J Endocrinol 193:157-169. 